\title{
7. Practising online with your peers: The role of text-chat for second language development
}

\author{
Marije Michel, Lancaster University
}

Written synchronous computer mediated communication (SCMC or text-chat) is a pervasive means of human interaction in modern society - in particular, among generations using social media. In a globalized world, SCMC often occurs in a second language (L2) and after two decades of research SCMC is an acknowledged context for L2 practice and development (Sauro 2011; Chun et al. 2016). Smith (2005: 34) identified text chat as 'the ideal medium for students to benefit from interaction' due to its specific nature: a hybrid between ephemeral interactive spoken and slow long-lasting written communication. In the context of meaningful interaction written SCMC creates relevant opportunities for learners to practice their L2 and to attend to and reflect on both the form and the content of an L2 message.

Little is known, however, in regard to how adolescents perceive peer interaction via SCMC as a medium of instruction and how it affects their language learning. This chapter aims to address these issues. It reviews the current literature on how and why peer interaction via SCMC may add to L2 development. In addition, data from an exploratory classroom-based study into practising L2 German via SCMC will be presented. Eighteen English high-school students performed a series of SCMC tasks and reported on their language learning motivation and anxiety as well as perception of the chat tasks. Chat logs were analysed for target structure use and accuracy. The discussion highlights the benefits and challenges of peer text chat interaction in the classroom as a context for second language practice. 


\section{Introduction}

As mentioned in chapter six (this volume), computer-based and mobile technology have increased the opportunity, in particular for foreign language learners, to make meaningful use of their second language (Gonzalez-Lloret and Ortega 2014; Adams et al. 2015). From a pedagogic perspective, reading online newspapers, watching YouTube movies or writing tweets in an L2 can be regarded as L2 practice. In this chapter, it is therefore assumed that these activities fit the broad definition of practice given in this volume as 'specific activities in the second language, engaged in systematically, deliberately, with the goal of developing knowledge of and skills in the second language' (DeKeyser 2007:1). The focus of the current chapter lies on written synchronous computer-mediated communication (SCMC or text-chat) in the L2 as a context for practice. After reviewing earlier work on L2 SCMC, particularly among language learning peers, this chapter will present an exploratory classroom-based study into practising L2 German via SCMC by English high-school students. The study discusses the use of the material and the output of the chat partner by L2 learners, learner production in terms of accuracy, L2 performance before and after SCMC practice and the relationship between language learning motivation and anxiety and task perceptions of participants. Finally, limitations of the study are presented alongside a discussion of the benefits and challenges of implementing peer text chat interaction as meaningful L2 practice.

\section{Previous research}

Written SCMC is a pervasive way of communication in modern society. In a globalised world, people often use text chat in a second or third language. A growing body of research has added to our understanding of how and why SCMC might add to L2 development (see Kern et al. 2008; Chapelle 2009; Sauro 2011; Ziegler 2016). However, the complex multimodal interplay of social and cognitive factors that are inherent to SCMC pose a major challenge to fully grasping the nature of text chat in an L2 (Chun et al. 2016). While some 
researchers compared SCMC with face-to-face (F2F) performance (e.g., Baralt and

Gurzinski-Weiss 2011; Baralt and Gurzynski-Weiss and Baralt 20112015) and looked at transfer from SCMC to spoken interaction (Payne and Whitney 2002), others have investigated L2 text chat in itself in order to understand how the specificities of SCMC affect L2 interaction and how this might support L2 development (e.g., Smith 2005; Sauro 2011). As an example of the phenomenon under investigation. Figure 1 gives an excerpt of a chat interaction between two L2 learners of English. The conversation shows some typical characteristics of written SCMC, which we can summarise as follows:

1. Turns are short and quickly following each other - 15 turns in less than 3 minutes making SCMC similar to spoken interaction.

2. The writing often overrules normative written standards as participants use abbreviations ( $r u$ instead of are you), elliptical structures (me too) rather than full sentences, deviate from standard spelling and punctuation (chinese without capital).

3. Turns are not always immediately contingent - the answer to the question in turn 11 appears in turn 15 .

4. One speaker may use several turns before leaving the ground to the partner (cf. turns 6-7 and 10-12).

\section{Figure 1}

Excerpt 'Social chat' pair A - Transatlantic chat project Michel \& Smith (20173)

\begin{tabular}{llll}
\hline Turn & Time & Name* $^{*}$ & Chat log \\
& {$[\mathrm{hh:mm:ss}]$} & & \\
\hline 1 & {$[18: 19: 45]$} & Karin & Hi this is Karin. \\
2 & {$[18: 19: 49]$} & Wendy & Hi \\
3 & {$[18: 19: 59]$} & Karin & r u Wendy? \\
4 & {$[18: 20: 15]$} & Wendy & yes, we should begin our little project?
\end{tabular}




$\begin{array}{llll}5 & {[18: 20: 36]} & \text { Karin } & \text { Yes, and nice to talk with you online. } \\ 6 & {[18: 20: 56]} & \text { Wendy } & \text { me too } \\ 7 & {[18: 21: 01]} & \text { Wendy } & \text { name? } \\ 8 & {[18: 21: 07]} & \text { Karin } & \text { Can I ask something about you? } \\ 9 & {[18: 21: 10]} & \text { Wendy } & \text { My name is Li Ten Zhi } \\ 10 & {[18: 21: 29]} & \text { Karin } & \text { My Chinese name is Xa Win. Karin is my English } \\ 11 & {[18: 21: 40]} & \text { Karin } & \text { How old r u now? } \\ 12 & {[18: 22: 02]} & \text { Karin } & \text { I think your English name sounds similar with your } \\ & & & \text { Chinese name too } \\ 13 & {[18: 22: 06]} & \text { Wendy } & \text { so is my English name, Wendy, sounds lke my } \\ 14 & {[18: 22: 12]} & \text { Karin } & \text { Yeah } \\ 15 & \text { Wendy } & \text { I am 24 years old, and I guess you are 21 ? }\end{array}$

Note. * Names have been anonymized.

Although the non-standard written language forms are sometimes seen as a threat to learning correct language use (Loewen and Reissner 2009), Smith (2005: 34) claims that written SCMC is 'the ideal medium for students to benefit from interaction' because it creates time, space and as such relevant opportunities for learners to attend to and reflect on both the form and the content of a message. Indeed, from a cognitive perspective, text chat does have some specific characteristics that can be beneficial for second language acquisition (SLA). First, SCMC has been referred to as interaction in slow motion (Beauvois 1992) given that most people type slower than that they speak, which results in a slower pace of turn-taking. At the conceptual level, written SCMC is similar to spoken conversation but it is performed in the 
written modality (Pelletieri 2000). Second, in contrast to ephemeral spoken interaction where everything said is gone within a few seconds, the output of text chat conversations remains visible. Once a chat partner has hit the enter key the contribution is transmitted and appears on the screen of both users. Consequently, L2 users have the possibility to look back to their own and their partner's production - for example to re-read a message that was not understood immediately or to draw on the interlocutor's linguistic forms for a new message ('copying' the partner). Third, text chat gives writers the possibility to review and edit their message before they transmit it to their partner. Finally, as voice and visual cues are absent in text chat learners have to use the linguistic means (e.g., pragmalinguistic markers) to frame speech acts (Sykes 2005). That is, while in spoken interaction L2 users may express themselves by intonation, gestures, and or frowns, text chat encourages them to use language (or sometimes emoticons) to transfer meaning, for example, using modals like could/would in a question instead of just raising intonation and eye brows.

\section{SCMC as a site for $\mathrm{L} 2$ practice}

These characteristics of SCMC have repeatedly been related to noticing (see Ziegler 2016 for a recent review and earlier chapters this volume for discussion of the benefits of noticing). As Sauro (2009: 96), puts it, SCMC is ideal 'for the learning of especially complex or low salient forms due to the visual saliency of certain forms'. Participants in Lai and Zhao (2006) demonstrated a high frequency of noticing of errors as revealed though stimulated-recall comments. Using screen-capture methods, Sauro and Smith (2010) showed that their participants engaged in frequent editing behaviour before sending a message, which improved the accuracy (in terms of correct language forms) and complexity (in terms of variety of word usage and greater syntactic diversity and density) of production. Smith (2010) employed eye-tracking technology to investigate noticing of intensive recasts, i.e., providing a corrected form as feedback to a learner's error, for example: Learner: I eat piece cake.- 
Tutor: You ate a piece of cake. Nice. Was it tasty? He revealed that learners attended to about $60 \%$ of the feedback, particularly, when recasts targeted lexical mistakes. The 'total' time of eye fixations on unknown lexical and grammatical forms during chat reported in Smith and Renaud (2013) correlated with post-test success on these structures.

Earlier work has also provided ample evidence of language related episodes (LREs) and beneficial negotiation processes (of meaning and to a lesser extent form) during SCMC (e.g., Blake 2000; Pelletieri 2000; Shekary and Tahririan 2006; Nik et al. 2012). LREs are instances of attention to the linguistic form (e.g., short discussion about the correct use of tense) during an otherwise meaning-focused communication (Swain and Lapkin 1998). Shekary and Tahririan's data (2006) demonstrated that LREs added to long-term retention of the negotiated forms and give evidence that the output practice provided by SCMC can facilitate noticing. While Blake (2000) highlights that SCMC creates opportunities for fruitful negotiation work outside the classroom (e.g., during homework tasks) his findings gave only minor support to negotiation of grammatical form. In contrast, Nik et al. (2012) found that L2 users displayed more negotiation of grammatical than of lexical form during text chat in academic contexts.

It is worth mentioning that the benefits for SLA that are attributed here to SCMC largely mirror those usually assigned to the role of interaction for SLA. Ever since Long (1996) formulated the Interaction Hypothesis the positive relationship between interaction and L2 production and development has been confirmed by numerous empirical studies in a variety of contexts (for reviews see meta-analyses by Mackey and Goo 2007 and Li 2010).

Accordingly, interaction in the L2 has shown to draw the learner's attention to input and output by means of negotiation processes, to promote noticing of potential gaps via positive and negative feedback, to create opportunities for hypothesis testing, and to require input and output processing which may lead to modification thereof (Gass and Mackey, 2007). 
Interaction is said to push L2 users from semantic to syntactic processing (Swain 1995) thereby raising the learner's awareness for linguistic form, which ultimately is said to promote language development (cf. Gass and Mackey 2007).

While earlier work (e.g., Pica et al. 1996; Swain and Lapkin 1998) had raised doubts about the benefits of peer interaction, Ortega (2007: 183) sees peer interaction as an essential principle for optimal L2 practice because collaboration creates 'L2 competence-expanding' opportunities. Other recent publications have shown that also learners can provide each other with effective feedback (see studies gathered in Philp et al. 2014). For example, Adams (2007) acknowledges that peers use a different range of feedback forms than native speaker (L1) interlocutors but states that its quality is not necessarily less valuable for language development. Effectiveness, however, seems to depend on task type and learning context. SCMC might well be the ideal context for peer interaction and therefore language acquisition (Smith 2010) due to its properties mentioned before, i.e., increased salience for both input and output processing, decreased (time) pressure and possibilities for sheltered practice. Nik et al. (2012) discuss SCMC as a context for writing-to-learn (Manchón 2011) where writing in the target language is seen as L2 practice that fosters linguistic processing which in turn facilitates language learning. This builds upon the idea that writing requires and thus helps L2 users to make relevant connections between form and meaning and to refine their knowledge and use of target language grammatical and lexical forms (Cumming 2001).

Nik et al. (2012) also argue that text chat is a unique medium to draw on a learners' natural urge to communicate in the written mode in order to practice their general writing skills, while Payne and Whitney (2002) demonstrated positive effects of practising in SCMC on follow-up spoken production. Along similar lines, Adams et al. (2015) highlight that the medium seems to promote engagement of more timid learners - an observation earlier commented on by Kern (1995: 470) who stated that text chat allows for 'unfettered self- 
expression, increased student initiative and responsiveness, generation of multiple perspectives on an issue, voicing of differences, and status equalization.' Text chat seems to create fairer and more balanced communicative settings between interactants than spoken communication.

Reviewing affective factors González-Lloret and Ortega (2014) suggest that technology mediated tasks in general have the potential to increase motivation, creativity and task engagement of language learners and lower language output anxiety. To date, there is little research that provides evidence for lower levels of language output anxiety during SCMC than during F2F. Comparing the two modalities, Baralt and Gurzynski-Weiss (2011) did not find differences in anxiety levels. However, perceptions of the SCMC tasks were positive irrespective of anxiety (see also chapter 6 this volume for further evidence of this). In her review on the topic, Ziegler (2016) concludes that more research is needed that investigates the relationship between anxiety on the one hand and L2 development and performance on the other hand.

The current chapter aims at filling some of the gaps addressed above. In particular, this study will explore practising an L2 by means of SCMC with a focus on (a) whether and how language learning peers improve their L2 knowledge as a result of the SCMC practice; (b) how they experience the use of SCMC in their language classroom; and (c) how they draw on each other's output during SCMC. In the following sections, a classroom-based study will be presented that examined L2 performance of English teenage users of German that interacted with each other in pairs by means of SCMC. Pairs worked on communicative tasks that were designed to elicit complex German clauses. The outcome of practice was monitored using a pre-, post-, delayed post-test design as well as by analysing learner production in terms of accuracy. Finally, the relationship between language learning motivation and anxiety and task 
perceptions of participants was taken into account and triangulated by interview data on their reported behaviour during the SCMC.

\section{Materials and Methodology}

In order to aid ecological validity (i.e., the generalizability to real-life settings) one of the aims of the present study was to collect data in a classroom during usual school hours generating the least interference of the research project as possible. In close cooperation with a German language teacher, the study was planned and performed at a girls-only high school in the northwest of England. Ethical approval from the researcher's institution and informed consent of the head of school as well as the participants and their parents was sought prior to the start of the project.

\section{Participants}

Eighteen female high-school students (mean age 14.5 years, $\mathrm{SD}=0.5$ ) learning German participated in the study. They were all English native speakers with some having an additional L1 (Azari, Ga, Punjabi, Spanish, and Twi). They had studied German for about 3.3 years $(\mathrm{SD}=1.8)$ and proficiency was around $\mathrm{A} 2$ of the CEFR as judged by their teacher. Participants themselves indicated that they have extensive experience in using a computer or mobile device, i.e., about 15 to 20 hours weekly, with up to six hours surfing the internet and up to four hours each being on social networks, interacting via text chat and doing their homework. Only limited time (30 minutes weekly) was spent on writing e-mails. A group of 14 female students from the same year and school (parallel German class) with similar characteristics participated in the pre- and post-test as a control group only (N.B. due to unexpected long-term absence of the teacher of the control group no delayed post-test data are available). 


\section{Target structures}

Target structures were chosen to be at the students' current level of development, to be general and frequent enough to occur in different task types and to be visually salient. The teacher indicated that students seemed to underuse complex German phrase structures even though they had been taught in class and were part of the year 10 curriculum. We chose two complex structures with word order deviations from English:

(1) German subordinate clauses introduced by the conjunctions 'weil', 'damit', 'dass' 'so dass' and 'wenn' (because, that, so that, when).

Subordinate clauses in German require the finite verb to be in sentence-final position. For example, in the subordinate clause of 'Das hört sich gut an, weil Göttingen eine interessante Stadt ist' (That sounds good because Göttingen is an interesting city) 'ist' is at the end. But the main clause equivalent 'Göttingen ist eine interessante Stadt' (Göttingen is an interesting city) uses verb second.

(2) German infinitive constructions either framed by 'um zu' (in order to) or the modal verbs 'kann', 'muss', 'möchte', ‘will' (can, has to, want to).

As before, the finite verb in the main clause 'Ich gehe nach Berlin' (I go to Berlin) moves to sentence-final position when an infinitive form is required, e.g., after a modal verb 'Ich will nach Berlin gehen' (I want to go to Berlin).

\section{Tasks}

The teacher and the researcher designed together three communicative tasks that matched topics within the students' curriculum so that they would be familiar with the vocabulary. We followed Ortega's (2007) principles for ideal practice tasks in that the tasks asked for meaningful peer interaction (via SCMC) and included a focus on form.

Task 1 asked peers to perform a pro-contra discussion with each other about a healthy lifestyle. Participants were assigned the role of a 'sports lover' or 'couch potato' respectively. 
Task 2 involved an interview about media use - one participant being the interviewer, the other being the interviewee. Task 3 asked participants to come up with a joint programme of activities for when a partner class from Germany would come to visit their city.

Focus on form was implicitly provided through the task material. That is, one participant of each conversational pair received a set of ten model sentences seeded with the target structure. Half of the collaborating pairs received model sentences with subordinate clauses, the other half received models with infinitive constructions. Participants were encouraged to use at least five of these sentences during the chat discussion. Appendix A gives the infinitives task sheet for task 2 .

\section{Pre-- and (delayed) post-_tests}

Three versions (items were placed in a different order for the pre-, post- and delayed posttest) of a paper-and-pencil grammaticality judgment test (GJT) with 25 dichotomous items were created with one sentence showing correct and one incorrect German word order. Apart from five filler items, half of the items targeted the correct word order in German complex subordinate and the other half in German infinitive structures, respectively. Five subordinate and infinitive sentences were copied from the model sentences of the tasks. Appendix B shows the instructions and example sentences of the GJT.

\section{Language learning motivation and task perception questionnaire}

An adapted version of the questionnaire designed by Kormos et al. (2011) was used to tap into pupil's language learning motivation and anxiety in German. On a 5-point Likert scale from strongly disagree to strongly agree, students decided on a total of 32 statements (four per construct) what was true for them. Statements targeted the following constructs: language learning anxiety, instrumental motivation, intrinsic motivation, motivational intensity, ideal L2 self, international orientation, peer pressure and parental encouragement. Six additional statements targeted anxiety students may feel when chatting in German and use of technology 
to support learning German (three statements each). Statements were presented in a randomized order.

Eight further questions (see Appendix C) required participants to rate their perceptions of the SCMC project and asked them to ticking three adjectives they associated most with the project (e.g., funny, boring). A set of final questions inquired about demographics and use of technology outside the classroom (e.g., time spent on surfing the internet, use of social networks).

\section{Focus group interview}

Finally, four volunteers from the experimental group participated in a short (15 minutes) focus group interview where they responded to questions targeting their perceptions of SCMC in the classroom and their use of language during the chat interactions (see Appendix D).

\section{Procedure}

The study used a pre-, post-, delayed_post-test design (cf. Figure 2) with three 20 minutes treatment tasks within the same week. Data collection was carried out by the participants' regular teacher during their usual classroom hours.

In the weeks before the data collection, the teacher informed the class about a 'Skype' project. They started with a practice session to familiarize themselves with the written chatfunction in Skype. Data collection started in the week thereafter. Participants did the written paper-and-pencil pre-test immediately before they performed on task 1 for twenty minutes. In the two following lessons within the same week, they performed for another 20 minutes each on task 2 and 3, respectively. For each task, participants were asked to work with the same partner and they were randomly assigned to group A (subordinate target structures) or B (infinitive target structures). At the end of every lesson, students copied their chat 
conversation into a word document and sent it by e-mail to the researcher. The last session was immediately followed by the written paper-and-pencil post-test.

Figure 2

Design and procedure

\begin{tabular}{|c|c|c|c|c|c|}
\hline Fri. wk 1 & Mon. wk 2 & Wed. wk 2 & Fri. wk 2 & Mon. wk 3 & Fri. wk 5 \\
\hline $\begin{array}{l}\text { Practice } \\
\text { with } \\
\text { Skype, } \\
\text { social chat } \\
\text { task: } \\
\text { Getting to } \\
\text { know } \\
\text { partner }\end{array}$ & $\begin{array}{l}\text { - GJT pre-test } \\
\text { (experimental and } \\
\text { control group) } \\
\text { - } 20 \text { mins chat } \\
\text { interaction } \\
\text { task 1: Pro-contra } \\
\text { discussion on } \\
\text { healthy life style }\end{array}$ & $\begin{array}{l}20 \text { mins chat } \\
\text { interaction } \\
\text { task } 2: \\
\text { Interview } \\
\text { about media } \\
\text { use }\end{array}$ & $\begin{array}{l}\text { - } 20 \text { mins chat } \\
\text { interaction task } \\
\text { 3: Joint } \\
\text { programme for } \\
\text { visitors } \\
\text { - GJT immediate } \\
\text { post-test } \\
\text { (experimental } \\
\text { and control } \\
\text { group) }\end{array}$ & $\begin{array}{l}\text { - Question- } \\
\text { naire } \\
\text { - Focus } \\
\text { group } \\
\text { interview }\end{array}$ & $\begin{array}{l}\text { GJT } \\
\text { delayed } \\
\text { post-test } \\
\text { (experi- } \\
\text { mental } \\
\text { group) }\end{array}$ \\
\hline
\end{tabular}

Three days after the last task performance, participants filled in the questionnaire. In addition, four participants took part in a focus group interview with the researcher to elaborate on their experiences. Three weeks after the last treatment the delayed post-test was administered.

\section{Coding}

All chat transcripts were manually coded for the use of the target structures according to the following categories:

(A) Model: subordinate/infinitive structures the participant had copied from her task sheet

(B) Creative: subordinate/infinitive structures either participant used creatively

Accuracy of use was determined based on sentence-final position of the main verb in obligatory contexts where obligatory contexts were (a) clauses introduced by a subordinate conjunction, or (b) infinitive constructions introduced by 'um zu' or a modal verb. Other mistakes (e.g. spelling errors) were disregarded for the purpose of this study.

Scores on the pre-, post- and delayed_-post-_tests are based on correct answers to critical items only (excluding filler items). Answers to the questionnaire items were aggregated into scores per construct (language learning motivation and anxiety) and reported as means in relation to the 5 point Likert scale as well as frequency of assigned answers (task perception). 
The focus group interview was transcribed and comments were used to complement the other data sources.

\section{Results}

This section reports on the results of this study. First, the use and accuracy of the target structures (complex German clauses) is reviewed to explore effects on L2 knowledge. Second, data on how the participants experienced the use of SCMC in their language classroom is shared. Finally, interview answers are highlighted that indicate how the teenagers used each other's output during SCMC.

During 20 minutes per task, pairs generated around 18 turns (Task 1: Mean 24.3, SD 17.9;

Task 2: Mean 16.7, SD 4.7; Task 3: Mean 18.0, SD 6.1) adding up to a total of 490 turns for all participants on all three tasks. A turn is defined as the language produced by one participant before hitting the enter key.

\section{Example chat interactions}

Figure 3 shows two excerpts of chat interactions by different pairs interacting on task 2 and task 3, respectively. In task 2, Tina (all names are changed for reasons of anonymity), uses two model subordinate sentences in turn 1 and 3. Her partner, Gabi, seems to follow her example in turn 5 and creates a subordinate clause introduced by the conjunction 'weil' with the finite verb 'chatte' in correct sentence final position.

In task 3 Irene starts with a model sentence from her task sheet. Her partner, Nina, picks up a very similar wording in her creative construction in turn 2 and follows with a second sentence in turn 3. Both times Nina places the finite verb in sentence final position. Unfortunately, the German conjunction 'denn' in turn 2 requires main clause word order (where the verb is in second position) and the word order is incorrect. In contrast, her creative utterance in turn 3 shows a correct verb-final structuresubordinate clause introduced by 'dass'. 
Figure 3

Example chat interactions.

Note. * is used by a chat partner to indicate a correction of an earlier erroneous form/typo

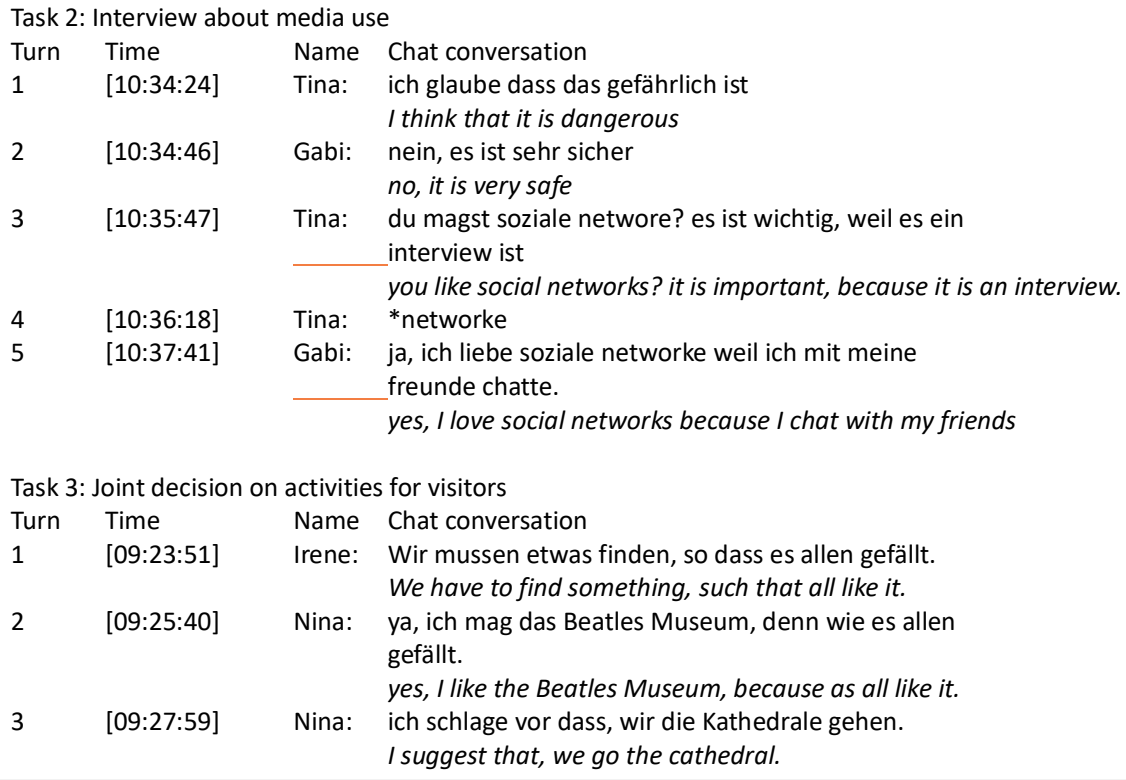

\section{Use of model target structures}

Table 1 gives the descriptive statistics for the use of model structures copied from the task sheet. Accordingly, participants employed around two models (even though the instruction asked for five). The standard deviations as well as the minimum/maximum scores reveal substantial individual differences, i.e., some students did not use any model sentence at all while others used more than instructed (6). The target structure groups differed such that the subordinate group demonstrates a decline, the infinitive group a steady growth from below to more than two instances of model sentence use over tasks. The total number of model structures copied from the task sheet was just above 80 instances (out of 490 total turns).

Table 2 
Use of model target structures from task sheet

\begin{tabular}{|c|c|c|c|c|c|c|c|}
\hline & Task & $\mathrm{N}$ & Mean & SD & Sum & Min & Max \\
\hline Subordinate & 1 & 8 & 2.13 & 2.42 & 17 & 0 & 6 \\
\hline \multirow[t]{2}{*}{ group } & 2 & 10 & 1.70 & 2.26 & 17 & 0 & 5 \\
\hline & 3 & 10 & 1.70 & 2.21 & 17 & 0 & 6 \\
\hline Infinitive & 1 & 8 & 1.75 & 2.05 & 14 & 0 & 5 \\
\hline \multirow[t]{2}{*}{ group } & 2 & 6 & 2.00 & 2.45 & 12 & 0 & 5 \\
\hline & 3 & 8 & 2.25 & 2.55 & 18 & 0 & 6 \\
\hline \multicolumn{2}{|c|}{ Total model sentence use } & $14^{\mathrm{a}}$ & 6.00 & 6.61 & 84 & 0 & 17 \\
\hline \multicolumn{8}{|l|}{ over all tasks } \\
\hline $\begin{array}{l}\text { a Due to abse } \\
\text { students fini }\end{array}$ & \multicolumn{7}{|c|}{ students finishing all three tasks). } \\
\hline
\end{tabular}

\section{Creative use of target structures}

Out of the 490 turns 86 contained a creatively used target structure. Participants produced infinitives (Mean 3.36, SD 3.27) more than subordinates (Mean 2.79, SD 2.91). Table 2 summarizes the creative use per task by target structure group.

Table 3

Creative use of subordinate or infinitive structures by group

\begin{tabular}{|c|c|c|c|c|c|c|c|}
\hline & \multicolumn{3}{|c|}{ Subordinate structures } & \multicolumn{3}{|c|}{ Infinitive structures } & \multirow[b]{2}{*}{$\overline{3}$} \\
\hline & Task & 1 & 2 & 3 & 1 & 2 & \\
\hline \multirow[t]{2}{*}{ Subordinate } & $\mathrm{N}$ & 8 & 10 & 10 & 8 & 10 & 10 \\
\hline & $\mathrm{Mn}$ & .50 & .60 & .60 & 1.13 & .20 & 2.60 \\
\hline \multirow[t]{3}{*}{ group } & $\mathrm{SD}$ & .76 & .70 & .97 & 1.25 & .42 & 1.71 \\
\hline & Med & .00 & .50 & .00 & 1.00 & .00 & 3.00 \\
\hline & Sum & 4 & 6 & 6 & 9 & 2 & 26 \\
\hline
\end{tabular}




\begin{tabular}{rlrrrrrr} 
& Min & 0 & 0 & 0 & 0 & 0 & 0 \\
& Max & 2 & 2 & 3 & 4 & 1 & 6 \\
\hline \multirow{5}{*}{ Infinitive } & $\mathrm{N}$ & 8 & 6 & 8 & 8 & 6 & 8 \\
& Mn & 1.88 & .17 & 2.13 & .25 & .67 & 2.38 \\
& SD & 2.95 & .41 & 2.36 & .46 & 1.63 & 1.85 \\
& Med & 1.00 & .00 & 1.50 & .00 & .00 & 2.50 \\
& Sum & 15 & 1 & 17 & 2 & 4 & 19 \\
& Min & 0 & 0 & 0 & 0 & 0 & 0 \\
& Max & 9 & 1 & 7 & 1 & 4 & 6 \\
& $\mathrm{~N}$ & 16 & 16 & 18 & 16 & 16 & 18 \\
& Mn & 1.19 & .44 & 1.28 & .69 & .38 & 2.50 \\
& SD & 2.20 & .63 & 1.84 & 1.01 & 1.03 & 1.72 \\
& Med & 1.00 & .00 & 1.00 & .50 & .00 & 3.00 \\
& Sum & 19 & 7 & 23 & 11 & 6 & 45 \\
& Min & 0 & 0 & 0 & 0 & 0 & 0 \\
& Max & 9 & 2 & 7 & 4 & 4 & 6 \\
\hline
\end{tabular}

Overall, numbers are low. Specifically, task 2 (the interview) did not elicit many target structures, while task 3 was more successful. Infinitives were creatively produced more often than subordinates, but a comparison of mean/median and min/max scores reveals that some individuals' usage is likely to have skewed the picture. For example, there are conversations where no creative subordinate or infinitive structure was produced while in task 1 one student from the infinitive group created as many as nine subordinates.

\section{Accuracy of creative target structure use}

Overall, 59\% (67 instances) of all creatively produced target structures were realized using correct word order with infinitives (63\%) being realized correctly more often than subordinates $(56 \%)$. The latter suggest performance at chance level. Accuracy by structure is summarized in Table 3. Again, numbers are generally low (1 to 2 instances), however, the means for both target structures show a steady growth from task 1 to task 2 and then task 3 . A trend that is visible in both the mean and the median value for infinitives.

Table 4

Accuracy of original subordinate and infinitive structures 


\begin{tabular}{lrrrrrr}
\hline & \multicolumn{5}{l}{ Subordinate structures } & \multicolumn{5}{l}{ Infinitive structures } \\
\hline Task & 1 & 2 & 3 & 1 & 2 & 3 \\
\hline $\mathrm{N}$ & 9 & 6 & 9 & 8 & 3 & 16 \\
Mean & .78 & 1.00 & 1.67 & .50 & 1.67 & 1.88 \\
SD & .83 & .63 & 1.94 & .54 & 2.08 & 1.59 \\
Med & 1.00 & 1.00 & 1.00 & .50 & 1.00 & 1.50 \\
Sum & 7 & 6 & 15 & 4 & 5 & 30 \\
Min & 0 & 0 & 0 & 0 & 0 & 0 \\
Max & 2 & 2 & 6 & 1 & 4 & 6 \\
\hline
\end{tabular}

\section{Pre and (delayed) post tests}

In Table 4 and 5 the (gain) scores on the grammaticality judgement test are reported for the experimental and the control group at the different points in time (pre-, post-, delayed posttest).

Table 5

Scores on pre-, post- and delayed post-test

\begin{tabular}{lllll}
\hline Percentage correct & Condition & N & Mean & SD \\
\hline Pre-test & Experimental & 18 & $64 \%$ & $12 \%$ \\
& Control & 13 & $57 \%$ & $10 \%$ \\
\hline Post-test & Experimental & 18 & $70 \%$ & $15 \%$ \\
& Control & 12 & $59 \%$ & $10 \%$ \\
\hline Delayed post-test & Experimental & 16 & $80 \%$ & $18 \%$ \\
& Control & & n/a & \\
\hline
\end{tabular}

The experimental group reached higher scores on the pre- and post-test than the control group and increased scores over time. Also gain scores were slightly higher in the experimental than control condition. As one-samples t-test on split files (experimental vs. control) revealed, for 
the experimental group differences approached significance when comparing pre- and posttest gains $(t(17)=1.93, p=.070)$, were significant when comparing pre- with delayed post-test gains $(\mathrm{t}(15)=5.126, \mathrm{p}<.001)$, but non-significant when comparing post- with delayed post-test gains $(t(15)=1.738, p=.103)$. In contrast, there was no significant difference between pre- and post-tests for the control group $(\mathrm{t}(10)=.906, \mathrm{p}=.386)$. No delayed post-test data are available due to unexpected long-term absence of the teacher of the control group.

Table 6

Gain scores from pre-to (delayed) post-test

\begin{tabular}{llcccc}
\hline Condition & Gain score & $\mathrm{N}$ & Mean & SD & SE \\
\hline Control & Pre to Post-test & 11 & 1.00 & 3.66 & 1.10 \\
\hline Experimental & Pre to Post-test & 18 & 1.39 & 3.05 & .72 \\
& Pre to Delayed post-test & 16 & 3.56 & 2.78 & .70 \\
& Post to Delayed post-test & 16 & 1.63 & 3.74 & .93 \\
& & & & & \\
\hline
\end{tabular}

\section{Language learning motivation and task perception}

As can be seen in Table 6, descriptives on task motivation and task perception reveal scores at the higher end ("agree") of the Likert scale for most constructs with intrinsic motivation, international orientation and parental encouragement showing particularly high means. Anxiety and chat anxiety were medium to low but the former showed large individual variation.

Table 6

Descriptives on task motivation and task perception ( $1=$ strongly disagree $-5=$ strongly agree) for all participants $(N=18)$ 


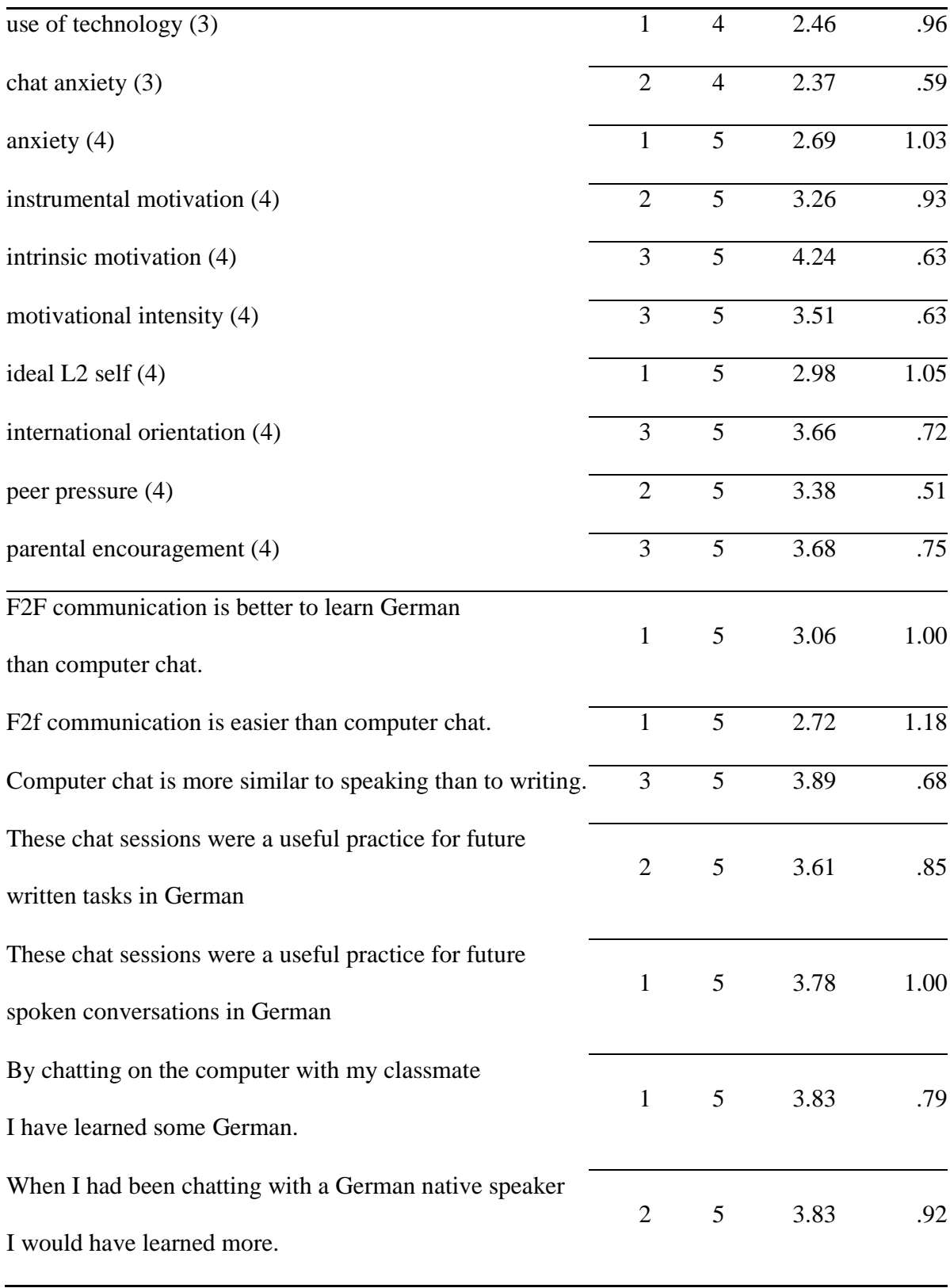

Also task perceptions reach mean scores at the higher end but individual variation is revealed by the $\min / \max$ values. Figure 3 presents the frequency of ratings on these questions. As the 
bar sections to the left (agree and strongly agree) reveal, most pupils found computer chat more similar to speaking than to writing and perceived SCMC as a useful means for practising German in particular for speaking. Most also thought that they had learned some German through the project, while just over half held the opinion that conversing with a German native speaker would have been more effective for L2 development. Perceptions were more mixed regarding comparisons between face-to-face communication $(\mathrm{F} 2 \mathrm{~F})$ and SCMC as some found F2F better and easier but others did value written chat higher.

Figure 3

Task perception - frequency of rating $(N=18)$

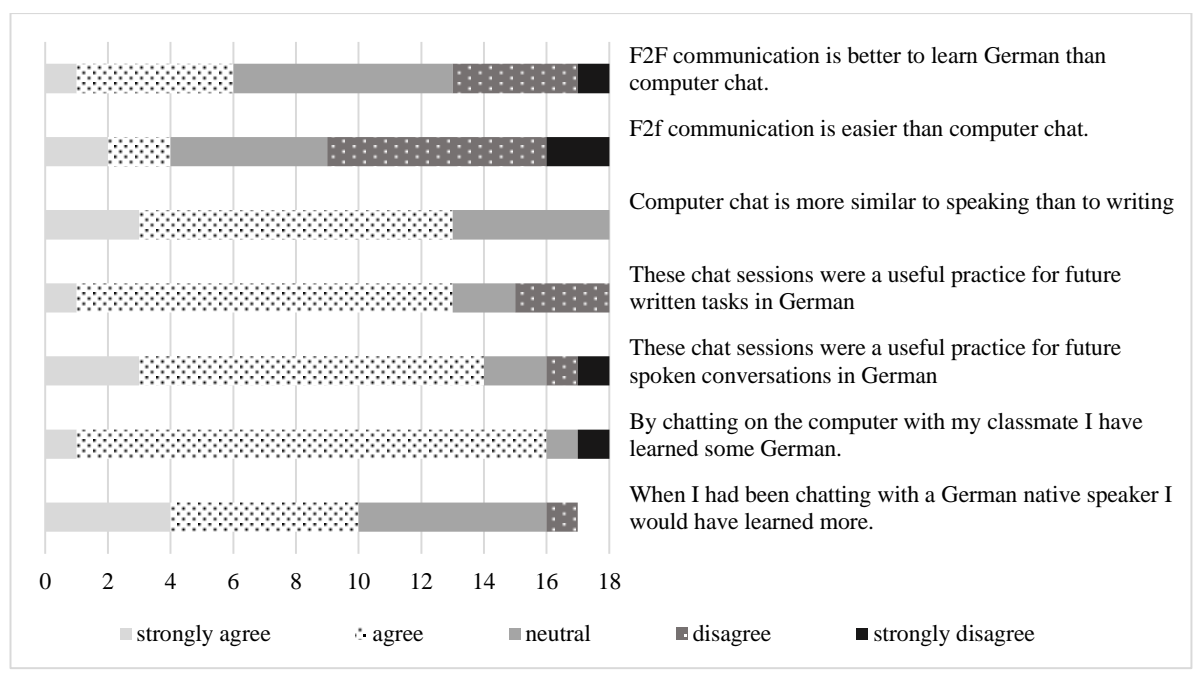

Given the small sample size and low total number of items Spearman correlations based on ranks were performed to investigate how the constructs related to each other. Table 7 summarizes the correlations for the underlying constructs of language learning motivation and anxiety $:-$ Table 8 provides the associations between motivation, anxiety and task perception. 
Some interesting findings concerning the specific SCMC context are the medium but significant relationship between the use of technology on the one hand and instrumental motivation, the ideal L2 self, international orientation and peer pressure. Chat anxiety showed only a medium relationship with language learning anxiety, which suggests that these are related but different constructs. Furthermore, the negative correlation with international orientation suggests that those who do have an international ambition, might see chat as a way to connect to people abroad.

Table 7

Spearman correlations of different aspects of language learning motivation

\begin{tabular}{|c|c|c|c|c|c|c|c|c|c|c|}
\hline & & 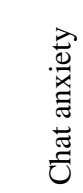 & 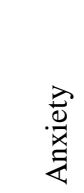 & 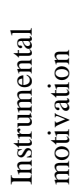 & 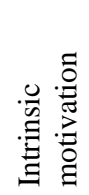 & 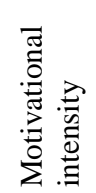 & 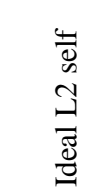 & 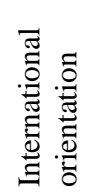 & 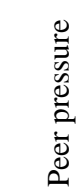 & 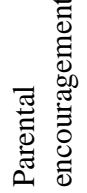 \\
\hline Use of & rho & -.103 & .282 & $.563^{*}$ & .287 & .271 & $.598^{* * *}$ & $.510^{*}$ & $.499^{*}$ & $\overline{-.103}$ \\
\hline technology & $\mathrm{p}$ & .683 & .256 & .015 & .248 & .277 & .009 & .031 & .035 & .685 \\
\hline Chat anxiety & $\begin{array}{l}\text { rho } \\
\mathrm{p}\end{array}$ & & $\begin{array}{l}.566^{*} \\
.014\end{array}$ & $\begin{array}{r}-.413 \\
.089\end{array}$ & $\begin{array}{r}-.283 \\
.255\end{array}$ & $\begin{array}{r}-.392 \\
.107\end{array}$ & $\begin{array}{r}-.437 \\
.070\end{array}$ & $\begin{array}{r}-.523^{*} \\
.026\end{array}$ & $\begin{array}{r}-.033 \\
.896\end{array}$ & $\begin{array}{r}-.013 \\
.960\end{array}$ \\
\hline Anxiety & $\begin{array}{l}\text { rho } \\
\text { p }\end{array}$ & & & $\begin{array}{r}-.466 \\
.051\end{array}$ & $\begin{array}{r}-.361 \\
.141\end{array}$ & $\begin{array}{r}-.296 \\
.232\end{array}$ & $\begin{array}{r}-.341 \\
.166\end{array}$ & $\begin{array}{r}-.331 \\
.180\end{array}$ & $\begin{array}{r}-.100 \\
.694\end{array}$ & $\begin{array}{r}-.360 \\
.142\end{array}$ \\
\hline Instrumental & $\begin{array}{l}\text { rho } \\
\text { p }\end{array}$ & & & & $\begin{array}{r}.610^{* *} \\
.007\end{array}$ & $\begin{array}{r}.643^{* *} \\
.004\end{array}$ & $\begin{array}{r}.791^{* *} \\
.000\end{array}$ & $\begin{array}{r}.592^{* *} \\
.010\end{array}$ & $\begin{array}{l}.505^{*} \\
.033\end{array}$ & $\begin{array}{l}.425 \\
.079\end{array}$ \\
\hline Intrinsic & $\begin{array}{l}\text { rho } \\
\text { p }\end{array}$ & & & & & $\begin{array}{r}.608^{* * *} \\
.007\end{array}$ & $\begin{array}{r}.558^{*} \\
.016\end{array}$ & $\begin{array}{l}.441 \\
.067\end{array}$ & $\begin{array}{l}.547^{*} \\
.019\end{array}$ & $\begin{array}{l}.326 \\
.186\end{array}$ \\
\hline $\begin{array}{l}\text { Motivational } \\
\text { intensity }\end{array}$ & $\begin{array}{l}\text { rho } \\
\text { p }\end{array}$ & & & & & & $\begin{array}{r}.816^{\text {** }} \\
.000\end{array}$ & $\begin{array}{l}.412 \\
.089\end{array}$ & $\begin{array}{l}.385 \\
.115\end{array}$ & $\begin{array}{c}.501^{*} \\
.034\end{array}$ \\
\hline Ideal L2 self & $\begin{array}{l}\text { rho } \\
\text { p }\end{array}$ & & & & & & & $\begin{array}{r}.735^{* *} \\
.001\end{array}$ & $\begin{array}{l}.550^{*} \\
.018\end{array}$ & $\begin{array}{l}.318 \\
.198\end{array}$ \\
\hline $\begin{array}{l}\text { International } \\
\text { orientation }\end{array}$ & $\begin{array}{l}\text { rho } \\
\text { p }\end{array}$ & & & & & & & & $\begin{array}{l}.538^{*} \\
.021\end{array}$ & $\begin{array}{l}.104 \\
.681\end{array}$ \\
\hline Peer pressure & $\begin{array}{l}\text { rho } \\
\text { p }\end{array}$ & & & & & & & & & $\begin{array}{l}.213 \\
.397\end{array}$ \\
\hline
\end{tabular}

Formatted: Font: English (United Kingdom)

Formatted: EndNote Bibliography, Line spacing: single Formatted: Font

Formatted: Line spacing: single

Formatted: Line spacing: single

Formatted: Line spacing: single

Formatted: Line spacing: single

Formatted: Line spacing: single

Formatted: Line spacing: single

Formatted: Line spacing: single

Formatted: Line spacing: single

The relationship between task perception and the motivational constructs reveal medium to

high associations between appreciation of the text chat tasks as a means to practice German 
and the use of technology, instrumental motivation and international orientation. The medium negative correlation between a positive task perception when comparing SCMC to F2F communication and anxiety could be seen as support for the use of text chat, in particular, for those who are anxious to speak in class. Finally, the absence of significant correlations between any task motivation construct and the statement that pupils felt they had learned some German from it, suggests that eventual benefits of L2 text chat can occur irrespective of learner motivation and anxiety.

Table 8

Spearman correlations of language learning motivation and chat task perception questionnaire

\begin{tabular}{|c|c|c|c|c|c|c|c|c|}
\hline & & 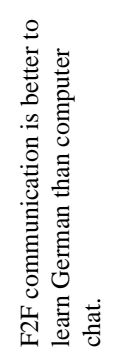 & 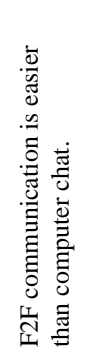 & 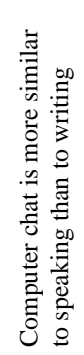 & 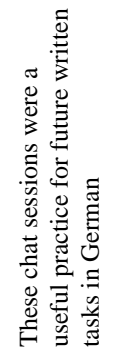 & 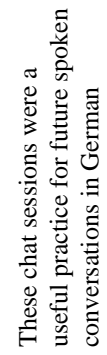 & 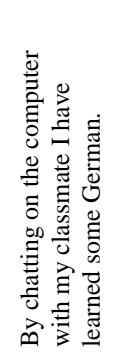 & 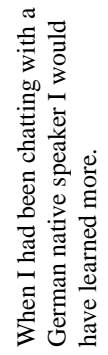 \\
\hline \multicolumn{2}{|c|}{ Use of technology rho } & -.467 & .122 & .339 & $.547^{*}$ & $.625^{* *}$ & .200 & -.407 \\
\hline & $\mathrm{p}$ & .051 & .631 & .169 & .019 & .006 & .427 & .093 \\
\hline Chat anxiety & $\begin{array}{l}\text { rho } \\
\text { p }\end{array}$ & $\begin{array}{l}-.220 \\
.380\end{array}$ & $\begin{array}{l}.087 \\
.732\end{array}$ & $\begin{array}{l}.154 \\
.543\end{array}$ & $\begin{array}{l}-.214 \\
.394\end{array}$ & $\begin{array}{l}-.271 \\
.277\end{array}$ & $\begin{array}{l}-.248 \\
.322\end{array}$ & $\begin{array}{l}.330 \\
.182\end{array}$ \\
\hline Anxiety & $\begin{array}{l}\text { rho } \\
\mathrm{p}\end{array}$ & $\begin{array}{l}.517^{*} \\
.028 \\
\end{array}$ & $\begin{array}{l}.275 \\
.269\end{array}$ & $\begin{array}{l}.294 \\
.236\end{array}$ & $\begin{array}{l}-.045 \\
.860 \\
\end{array}$ & $\begin{array}{l}-.059 \\
.817 \\
\end{array}$ & $\begin{array}{l}-.045 \\
.860\end{array}$ & $\begin{array}{l}.102 \\
.689 \\
\end{array}$ \\
\hline Instrumental & $\begin{array}{l}\text { rho } \\
\mathrm{p}\end{array}$ & $\begin{array}{l}.074 \\
.772 \\
\end{array}$ & $\begin{array}{l}-.095 \\
.708 \\
\end{array}$ & $\begin{array}{l}.045 \\
.859 \\
\end{array}$ & $\begin{array}{l}.701^{* * *} \\
.001 \\
\end{array}$ & $\begin{array}{l}.601^{* * *} \\
.008 \\
\end{array}$ & $\begin{array}{l}.352 \\
.152 \\
\end{array}$ & $\begin{array}{l}.284 \\
.253 \\
\end{array}$ \\
\hline Intrinsic & $\begin{array}{l}\text { rho } \\
\mathrm{p}\end{array}$ & $\begin{array}{l}-.158 \\
.532\end{array}$ & $\begin{array}{l}.130 \\
.607\end{array}$ & $\begin{array}{l}-.209 \\
.405\end{array}$ & $\begin{array}{l}.280 \\
.260\end{array}$ & $\begin{array}{l}.202 \\
.421\end{array}$ & $\begin{array}{l}-.021 \\
.934\end{array}$ & $\begin{array}{l}-.213 \\
.396\end{array}$ \\
\hline $\begin{array}{l}\text { Motivational } \\
\text { intensity }\end{array}$ & $\begin{array}{l}\text { rho } \\
\text { p }\end{array}$ & $\begin{array}{l}.342 \\
.164\end{array}$ & $\begin{array}{l}.201 \\
.425\end{array}$ & $\begin{array}{l}-.037 \\
.883\end{array}$ & $\begin{array}{l}.488^{*} \\
.040\end{array}$ & $\begin{array}{l}.114 \\
.654\end{array}$ & $\begin{array}{l}.290 \\
.243\end{array}$ & $\begin{array}{l}.206 \\
.413\end{array}$ \\
\hline Ideal L2 self & $\begin{array}{l}\text { rho } \\
\text { p }\end{array}$ & $\begin{array}{l}.252 \\
.314\end{array}$ & $\begin{array}{l}.235 \\
.347\end{array}$ & $\begin{array}{l}.211 \\
.402\end{array}$ & $\begin{array}{l}.582^{*} \\
.011\end{array}$ & $\begin{array}{l}.464 \\
.052\end{array}$ & $\begin{array}{l}.265 \\
.289\end{array}$ & $\begin{array}{l}-.005 \\
.983\end{array}$ \\
\hline \multirow[t]{2}{*}{$\begin{array}{l}\text { International } \\
\text { orientation }\end{array}$} & $\begin{array}{l}\text { rho } \\
\mathrm{p}\end{array}$ & $\begin{array}{l}.128 \\
.612 \\
\end{array}$ & $\begin{array}{l}.378 \\
.122 \\
\end{array}$ & $\begin{array}{l}.244 \\
.329 \\
\end{array}$ & $\begin{array}{l}.553^{*} \\
.017 \\
\end{array}$ & $\begin{array}{l}.640^{* *} \\
.004 \\
\end{array}$ & $\begin{array}{l}.444 \\
.065\end{array}$ & $\begin{array}{l}-.181 \\
.472 \\
\end{array}$ \\
\hline & rho & -.122 & .205 & $\begin{array}{l}.179 \\
\end{array}$ & .303 & .345 & .385 & .026 \\
\hline
\end{tabular}

Formatted: Font: English (United Kingdom) Formatted: EndNote Bibliography

Formatted: Font: 


\begin{tabular}{lllllllll} 
Peer pressure & $\mathrm{p}$ & .629 & .414 & .477 & .222 & .160 & .115 & .919 \\
\hline Parental & $\mathrm{rho}$ & .365 & -.273 & .054 & .191 & -.041 & .201 & .067 \\
encouragement & $\mathrm{p}$ & .136 & .273 & .830 & .447 & .872 & .423 & .792 \\
\hline
\end{tabular}

\section{Focus group interview}

Four participants took part in a semi-structured focus group interview three days after their last task performance. Questions targeted the SCMC context (e.g., What would have been different if you had talked to each other rather than chatted?) as well as language during chat (e.g., Do you think you have learned something from each other?), cf. Appendix D. Below three excerpts from the interview are given. 
10 P3: And it helped me learned new vocabulary and ehm eh like... even if you make mistakes they like. It could still be right.

11 R: So you said you learned some new vocabulary. Do you think you learned something from each other?

12 All P: yeah, yeah yeah...

13 P1: eh how like other people kind of write in German. How they structure their sentences.

14 P2: yeah yes...

15 P4: They helped some like with GCSE writings and that, sometimes speaking.

16 R: You said you've learned words? Did you look back how the sentences were built?

17 All P: yeah, yeah, yes

18 P3: like to see how different people would say the things like... because you'd see how they'd say it and then you'd see how you would write them and compare them and see which way is better so to think

In Excerpt 1, Interviewee 1 and 3 indicate that they used the output of their partner as a

model for their own structural choices. The same holds for Interviewee 2 in Excerpt 2. This participant also indicates that she used the task sheet as a model when writing her

contributions.

\section{Excerpt 2 (turns $44-48)$}

44 P2: And when you see your answer. When you see their answer you can use that. When like, say if you're asking the questions and they're answering $\mathrm{it}_{2}=$ you can use that ${ }_{2}$ like $_{2}$ what they said. And work on it.

45 R: Like you would copy it at bit?

46 P1: yeah, change it...

47 P3: It's also, like, you don't know what they're gonna send back, so it's kind of like, put you on the spot and kind of like, $_{2}$ to see how you'd react and what happens in real life.

48 P2: Like, when you... when you're waiting for ${ }_{2}$ like, someone else, I always looked at the paper next to me to see what they'd put and I'd see ${ }_{2}$ they have said that, I could may-be use that and say it in a different way and ... to get some idea's.

In Excerpt 3 the interviewees discuss the fact that SCMC allows them to think more

profoundly than spoken interaction and that this reduces (time) pressure. 
From all three excerpts it is apparent that the SCMC environment allowed participants to

'look at' and 'see' the German in the chat window and that they used this for their subsequent production.

Excerpt 3 (turns $35-40$ )

$35 R$ : Are there other reasons why it is more difficult in spoken?

36 P1: I would actually say it is more difficult, like, writing, because, like, when you're speaking you can use gestures. Which you cannot do in writing.

37 P4: But I think ${ }_{2}$ like, you know when you've got it written down and you had some time, you'll think of it and you'll get back to the start and you'd had forgotten the word. When now, I've got that bit now, what do I need?

38 P3: and And like with word order, you can see. Like, it helps me when you look at something. To know where to put the word and whether it looks right ${ }_{2}$ rather than if it sounds right. That's just like, $_{2}$ for me.

39 All P: yeah...

40 P1: I was thinking, you got a bit more time to think as well. Because when, like ${ }_{2}$ you're speaking you feel like you have to reply straight away. Whereas, like $_{2}$ when you're writing it, you can kind of take a minute time to think. Aand then correct it $\underline{i}$. If you're wrong and then send it.

\section{Discussion}

The present chapter discusses L2 practice by means of SCMC. It presents and explorative study into collaborative tasks between L2 learning peers carried out via text chat. Eighteen English teenagers that learned German performed three communicative chat tasks that were seeded with models of complex subordinate and infinitive structures. The explorative nature of the current study based on a (-small data set do not allow for any conclusive statements.

Keeping these caveats in mind, however, findings do suggest that task performance did function as L2 practice that added to target language development.

\section{Guided practice via peer interaction in written SCMC}

The first aim of this study was to see whether and how language learning peers improve their L2 knowledge as a result of the SCMC practice. On average, pupils did use six of the model 
sentences and came up with one creative use during the chat interactions. Some individual performances reveal even 17 model sentences and 6 creative productions (others, however, did not use any). Steady growth in accuracy was visible from task 1 to task 3 and seemed to be beyond chance level for infinitive structures in the end. Results for the grammaticality judgement tests point into the same direction. Hence students' knowledge of the target structures in the experimental group did improve, while the control group did not show improvements. Together, these findings lend support to the perspective that task-based practice via SCMC can supports foster $\mathrm{L} 2$ development.

It is likely that the minor findings are related to the choice of target structure. We followed Ortega's (2007) principles for ideal practice tasks and designed material that allowed meaningful peer interaction. Tasks were aligned with the curriculum of the students and target structures were expected to be known. Yet, the focus on the target structures was implemented implicitly, that is, as seeded model sentences provided to one participant per pair. Students were encouraged to use the models, but chat logs demonstrated that participants had a strong preference for one or two forms, which they kept using (e.g., one pair alternated between 'weil' and 'dass' creating nine original subordinate structures in task 1) at times irrespective of model sentence. As the absence of creative use in task 2 furthermore suggests, target structures were not task essential and might not even natural in some tasks (Loschky and Bley-Vroman 1993). Presumably, the argumentative discussions in task 1 and 3 more naturally elicited the complex target structures than the interview in task 2. It is important to acknowledge that the quantitative figures focus on the use, accuracy and development of the two target structures.

However, qualitative examinations of the chat logs and the interviews point towards L2 practice with a much wider scope - and this answers a further aim of this study, i.e., to explore how L2 users draw on each other's output during SCMC. When writing their 
contributions, students in this study used all the material they had available (e.g., model sentences, output of their partner) both at the structural (word order) and lexical (e.g., 'es allen gefällt' in example 2) level. Interviewees mentioned that they looked at the output of their partner when formulating messages, evaluating whether they could use this language in their own performance. The eye-tracking work by Michel and Smith (submitted2017) suggests indeed that lexical items in the partner output that receive heightened attention (more eye fixations) are likely to be used in subsequent production - a phenomenon that could be linked to strategic alignment (Costa, Sorace and Pickering 2008). Future work might consider including a wider scope of forms and analyse peer interaction using corpus techniques to identify overlap and convergence (Collentine and Collentine 2013) in order to receive a better understanding what language peers practice when they chat with each other. Similar to earlier work (Smith 2005; Sauro 2009), post-performance questionnaire data as well as the focus group interviews confirm that the chat environment allowed students more time to think about their production and focus on form because the conversation remained visible and because participants were able to edit their contributions before transmitting their message. The current data therefore are in line with earlier work that relates SCMC to enhanced noticing and form-focused behaviour.

\section{Language learning motivation, anxiety and task perception}

The second aim of this study was to explore how teenage L2 users experience the use of SCMC in their language classroom. As such, this study is one of the first that evaluates language learning motivation and anxiety in relation to task perception (Ziegler 2016).

Overall, students in this study displayed medium to high motivation, medium anxiety and fairly high appreciation of the SCMC tasks. Crucially, participants perceived the tasks to be a useful practice for both written and more so spoken interaction - which provides support from teenage $\mathrm{L} 2$ users for the theoretical characterisation of SCMC as a hybrid between 
speaking and writing (Pellettieri 2000). The fact that chat anxiety did not correlate with any of the task perception questions indicates that it did not play a major role in their appreciation of the project. Note that language output anxiety was associated with a greater appreciation of SCMC.

Finally, two further aspects are worth noting: $89 \%$ of the participants in this study agreed that they had learned something from the tasks. It is remarkable that this statement did not correlate with any of the motivational constructs, suggesting that perceived learning might not be mediated by motivation. Still, $55 \%$ indicated that chatting with a native speaker would have been more beneficial. A statement that was reiterated as an open comment in the questionnaire: 'I would have found that talking to an actual German person would have been better than talking to my friend as my main aim was to have her understand me and get my point across rather than focusing on my German grammar.' Future work might explore task perceptions, chat anxiety and language learning motivation in a comparison of peer nonnative versus native-non-native SCMC context.

\section{Conclusion}

This chapter explored practice of a second language via SCMC between adolescent peers. An exploratory classroom-based study revealed that tasks designed to implicitly focus L2 learners' of German on word order in complex clauses did elicit some (accurate) target structure use and gain scores showed significant improvement over time. Questionnaire data on language learning motivation, anxiety and task perception revealed further insights, e.g., that students think they had learned something irrespective of their motivation. Interview and questionnaire data, point to another positive side-effect of using written SCMC: the teenage girls learning German appreciated the 'Skype project'. 'Helpful' (n=12), 'refreshing' (n=9) and 'exciting' $(\mathrm{n}=8)$ were the most ticked answers when participants were asked about the characteristics of chatting with their peers. 
To sum up, even though the sample size is too small and some other limitations (e.g., no delayed post-test for control group; girls-only classroom) do not allow firm conclusions, the current data set was able to give some valuable insights into L2 practice via SCMC. Above all, the text chat project has shown to be an engaging learning environment for the teenage participants studying German. Overall, this chapter supports earlier work into computer chat: written SCMC presents a unique medium of interaction that is valued by the students and as such, creates a fruitful context for L2 practice and development.

\section{Acknowledgement}

I thank the school, teacher and pupils for their participation as well as Ursula Weinberger for her help with coding. I also owe thanks to the editor and anonymous reviewers of earlier versions of this chapter.

\section{References}

Adams R. 2007. 'Do second language learners benefit from interacting with each other?', in Mackey, A (ed.) Conversational interaction in second language acquisition. Oxford: Oxford University Press, 29-52.

Adams, R., Alwi, N.A.N.M. and Newton, J.2015. 'Task complexity effects on the complexity and accuracy of writing via text chat', Journal of Second Language Writing 29: 64-81

Baralt, M. and Gurzynski-Weiss, L. 2011. 'Comparing learners' state anxiety during taskbased interaction in computer-mediated and face-to-face communication', Language Teaching Research 15(2): 201-229.

Beauvois, M. H. 1992. 'Computer-assisted class-room discussion in the foreign language class-room: Conversation in slow motion', Foreign Language Annals 25: 455-64.

Blake, R., 2000. 'Computer mediated communication: A window on L2 Spanish interlanguage', Language Learning \& Technology 4(1): 120-136.

Chun, D., Smith, B. and Kern, R. 2016. 'Technology in language use, language teaching, and language learning', The Modern Language Journal 100(S1): 64-80.

Collentine, J., and Collentine, K. 2013. 'A corpus approach to studying structural convergence in task-based Spanish L2 interactions', in McDonough, K. and Mackey, A. (eds.), Second language interaction in diverse educational contexts.

Amsterdam/Philadelphia: John Benjamins, 167-187.

Costa, A., Pickering, M.J. and Sorace, A., 2008. 'Alignment in second language dialogue', Language and Cognitive Processes 23(4): 528-556.

Cumming, A., 2001. 'Learning to write in a second language: Two decades of research', International Journal of English Studies 1(2): 1-23. 
DeKeyser, R. (ed.) 2007. Practice in a Second Language: Perspectives from Applied Linguistics and Cognitive Psychology. Cambridge: Cambridge University Press.

Ellis, R. 2009. 'Task-based language teaching: sorting out the misunderstandings', International Journal of Applied Linguistics 19(3): 221-246. doi:10.1111/j.14734192.2009.00231.x

Gass, S. M., and Mackey, A. 2007. 'Input, interaction, and output in second language acquisition' in VanPatten B. and Williams, J. (eds.), Theories in second language acquisition. An introduction. 'Mahwah, NJ: Lawrence, 175-199.

Gass, S., and Varonis, E. 1989. 'Incorporated repairs in nonnative discourse' in Eisenstein, M. (ed.), The dynamic interlanguage: Empirical studies in second language variation. New York: Plenum Press, 71-86.

González-Lloret, M., and Ortega, L. 2014. 'Towards technology-mediated TBLT: An introduction' in González-Lloret, M. and Ortega, L. (eds.) Technology-mediated TBLT: Researching technology and tasks. Amsterdam/Philadelphia: John Benjamins, 1-22.

\section{Gurzynski-Weiss, L., and Baralt, M. 2015. 'Does type of modified output correspond to learner noticing of feedback? A closer look in face-to-face and computer-mediated task-based interaction', Applied Psycholinguistics 36(6): 1393-1420. doi:10.1017/S0142716414000320}

Kormos, J., Kiddle, T. and Csizér, K. 2011. 'Goals, attitudes and self-related beliefs in second language learning motivation: an interactive model of language learning motivation', Applied Linguistics 32(5): 495-516.

Kern, R. 1995. 'Restructuring classroom interaction with networked computers: Effects on quantity and characteristics of language production', The Modern Language Journal 79: 45776.

Kern, R., Ware, P. and Warschauer, M. 2008. 'Network-based language teaching' in Encyclopedia of language and education. Springer US, 1374-1385.

Lai, C., and Zhao, Y. 2006. 'Noticing and text-based chat', Language Learning and Technology 10(3): 102-120.

Li, S. 2010. 'The effectiveness of corrective feedback in SLA: A meta-analysis', Language Learning 60(2): 309-365. doi:10.1111/j.1467-9922.2010.00561.x

Loewen, S. and Reissner, S. 2009. 'A comparison of incidental focus on form in the second language classroom and chatroom', Computer Assisted Language Learning 22(2): 101-114.

Long, M.H. 1996. 'The role of the linguistic environment in second language acquisition' in Ritchie, W.T. and Bhatia, T.K. (eds.) Handbook of language acquisition: Vol. 2. Second language acquisition. New York, NY: Academic Press, 413-468.

Loschky, L. and Bley-Vroman, R. 1993. Grammar and task-based methodology. Multilingual Matters, 123-123.

Mackey, A., and Goo, J. 2007. 'Interaction research in SLA: A meta-analysis and research synthesis' in Mackey (ed.), 407-452.

Mackey, A., Oliver, R. and Leeman, J. 2003. 'Interactional input and the incorporation of feedback: an exploration of NS-NNS and NNS-NNS adult and child dyads', Language Learning 53: 35-66. doi: 10.1111/1467-9922.00210

Manchón, R. (ed.) 2011. Learning-to-write and writing-to-learn in an additional language. Amsterdam/Philadelphia: John Benjamins. 
Michel, M. and Smith, B. submitted2017.- 'Measuring lexical alignment during L2 peer interaction via written synchronous computer-mediated communication - An eye-tracking study', in S. Gass, P. Spinner, and J. Behney (eds.), Salience and SLA. Routeledge.

Nik, A.A.N.M., Adams, R. and Newton, J. 2012. 'Writing to learn via text chat: Task implementation and focus on form', Journal of Second Language Writing 21(1): 23-39.

Ortega, L. 2007. 'Meaningful L2 practice in foreign language classrooms: A cognitiveinteractionist SLA perspective', in R. DeKeyser (ed.), Practising in a second language: Perspectives from applied linguistics and cognitive psychology. New York: Cambridge University Press, 180-207.

Payne, J.S. and Whitney, P.J. 2002. 'Developing L2 oral proficiency through synchronous CMC: Output, working memory, and interlanguage development', CALICO Journal: 7-32.

Pelletieri, J. 2000. 'Negotiation in cyberspace: The role of Chatting in the development of grammatical competence', in Warschauer, M. and Kern, R. (eds.), Network-based language teaching: Concepts and practice. New York: Cambridge University Press, 59-86.

Philp, J., Adams, R. and Iwashita, N. 2013. Peer interaction and second language learning. New York: Taylor and Francis.

Pica, T., Lincoln-Porter, F., Paninos, D., and Linnell, J. 1996. 'Language learners' interaction: How does it address the input, output, and feedback needs of L2 learners?', TESOL Quarterly 30(1): 59-84. doi:10.2307/3587607

Sauro, S. 2009. 'Computer-mediated corrective feedback and the development of L2 grammar', Language Learning and Technology 13(1): 96-120.

Sauro, S. 2011. 'SCMC for SLA: A research synthesis', CALICO Journal 28(2), 369-391.

Sauro, S. and Smith, B. 2010. 'Investigating L2 performance in text chat', Applied Linguistics 31(4): 554-577.

Shekary, M. and Tahririan, M.H. 2006. 'Negotiation of meaning and noticing in text-based online chat', The Modern Language Journal 90(4): 557-573.

Smith, B. 2005. 'The relationship between negotiated interaction, learner uptake, and lexical acquisition in task-based computer mediated communication', TESOL Quarterly 39(1): 3358.

Smith, B., 2010. 'Employing eye-tracking technology in researching the effectiveness of recasts in CMC in Directions and prospects for educational linguistics' in Hult, F.M. (ed.) Directions and Prospects for Educational Linguistics. New York: Springer, 79-97.

Smith, B., and Renaud, C. 2013. 'Using eye-tracking as a measure of foreign language learners' noticing of recasts during computer-mediated writing conferences', in McDonough and Mackey (eds.), 147-165.

Swain, M. 1995. 'Three functions of output in second language learning', in Cook, G. and Seidlhofer, B. (eds.), Principle and practice in applied linguistics. Oxford: Oxford University Press, $125-144$.

Swain, M., and Lapkin, S. 1998. 'Interaction and second language learning: Two adolescent French immersion students working together', The Modern Language Journal 82(3): 320337.

Sykes, J.M., 2005. 'Synchronous CMC and pragmatic development: Effects of oral and written chat', CALICO Journal: 399-431. 
Ziegler, N. 2016. 'Taking technology to task: technology-mediated TBLT, performance, and production', Annual Review of Applied Linguistics 36: 136-163.

\section{Appendices}

A Example task 2: Infinitive

\section{TASK 2: Mein Leben online}

\section{Read the following texts before undertaking the chat task}

Group B: You are a journalist for Sankt Anna's school magazine. You are going to conduct an interview with a pupil from your partner school, St Mary's, to see how much time she spends with new media, and what activities she does.

This interview will last 20 mins and you will start.

Before the interview you will note down the questions you are going to ask. Please include a minimum of 5 sentences from the following list:

- Das kann ich nicht verstehen. Was meinst du?

- Ich mochte das anders aufschreiben.

- Ich frage das, um dich zu zitieren.

- Ich will das gerne anders erklären.

- Das kann ich nicht in der Schulzeitung verwenden.

- Ich finde es schlimm, das zu hören.

- Man muss immer genau sein.

- Ich finde es komisch, das zu fragen.

- Ich frage das, um ein Argument zu haben.

- Man sollte das anders machen, nicht wahr? 
B Example pre-, post-, delayed post-test

Ticked boxes $\square$ indicate correct answer for filler, subordinate (sub.) and infinitive (inf.)

sentences

\section{Short Quiz}

In the following you see a list of German sentences. In some of them, the word order is mixed up. Please tick for each pair of sentences the one you think is correct.

Example:

冈 Maria isst einen Apfel. (Mary eats an apple.)

- Ein Petra isst Brot. (A Petra eats bread.)

\begin{tabular}{|c|c|c|}
\hline \multirow[t]{2}{*}{ I. } & D Sandra ist am Bahnhof und Fahrkarte eine kauft. & \multirow[b]{2}{*}{ च Filler } \\
\hline & - Karin geht gerne ins Museum und in die Bibliothek. & \\
\hline \multirow[t]{2}{*}{2.} & Darah glaubt, dass die Ducktour gefährlich ist. & \multirow[t]{2}{*}{$\nabla$ Sub. } \\
\hline & $\square$ Ich denke, dass es gefallt mir. & \\
\hline \multirow[t]{2}{*}{3.} & $\square$ Es ist schlimm, wenn man macht das. & \multirow[b]{2}{*}{$\square$ Sub. } \\
\hline & $\square$ Paula ist schlecht gelaunt, wenn sie Hunger hat. & \\
\hline \multirow[t]{2}{*}{4.} & Daniela ruft mich an, damit ich vergesse es nicht. & \multirow[b]{2}{*}{ ఐ Sub. } \\
\hline & $\square$ Das musst du besser begründen, damit ich dir glaube. & \\
\hline \multirow[t]{2}{*}{5.} & $\square$ Judit möchte das anders aufschreiben. & \multirow[t]{2}{*}{ ఐInf. } \\
\hline & Ich möchte lösen das Problem morgen. & \\
\hline
\end{tabular}




\section{Questionnaire items on task perception}

\section{SOME QUESTIONS ABOUT THIS PROJECT}

What do you think about using chat in your German class? Tick the three answors that are most appropriate

\begin{tabular}{|c|c|c|c|c|c|c|c|c|}
\hline & boring & distracting & & excit & & & uperflu & \\
\hline & 무 & ㅁ. & & a & & & 口 & \\
\hline & useful & important & & labori & & & efreshi & \\
\hline & 므 & ㅁ & & I & & & ㅁ & \\
\hline & & & 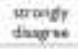 & draget & doter & $\begin{array}{l}\text { didal, } \\
\text { anes }\end{array}$ & था\% & strongty \\
\hline a. & $\begin{array}{l}\text { By chattin } \\
\text { learned sc }\end{array}$ & $\begin{array}{l}\text { inputer with my classmace I have } \\
\text { in. }\end{array}$ & la & 므 & ㅁ & 므 & 믄 & ㅁ \\
\hline b. & $\begin{array}{l}\text { When I h } \\
\text { I would hy }\end{array}$ & $\begin{array}{l}\text { tting with a German native speaker } \\
\text { more. }\end{array}$ & 미 & 므 & ㅁ & ㅁ & ㅁ & 미 \\
\hline c. & $\begin{array}{l}\text { These ch } \\
\text { spoken ce }\end{array}$ & $\begin{array}{l}\text { were a useful practice for future } \\
\text { s in German. }\end{array}$ & 마 & 마 & 무 & 므 & D & 마 \\
\hline d. & $\begin{array}{l}\text { These cha } \\
\text { written ta }\end{array}$ & $\begin{array}{l}\text { were a helpful practice for future } \\
\text { nan. }\end{array}$ & 마 & 마 & ㅁ & ㅁ & $\square$ & 미 \\
\hline e, & $\begin{array}{l}\text { Compute } \\
\text { German. }\end{array}$ & ore similar to speaking than to writing & a & 다 & ㅁ & 口 & ㅁ & ㅁ \\
\hline f. & $\begin{array}{l}\text { Face-to-th } \\
\text { by compu } \\
\text { Whyl... }\end{array}$ & hication is easier than communication & fa & II & 口 & 口 & 미 & $\square$ \\
\hline z & $\begin{array}{l}\text { Facc-to-th } \\
\text { computer } \\
\text { Why?... }\end{array}$ & pication is becter to learn German than & 0 & $\overline{0}$ & 口 & 口 & D & ㅁ. \\
\hline h. & $\begin{array}{l}\text { After this } \\
\text { Why!... }\end{array}$ & co learning German more than before. & 마 & 마 & 미 & ㅁ & ㅁ & D \\
\hline
\end{tabular}

\section{Transcript focus group interview}

Participants: Researcher (R) and four participants of experimental group (P1-4)

N.B. Data were transcribed as closely as possible to the spoken answers of the participants.

Therefore, many elliptical utterances and spoken forms are visible.

\begin{tabular}{|l|l|}
\hline 1 & $\begin{array}{l}\text { R: What did you like most about it, or do you think there was something that was } \\
\text { especially difficult or or so...? }\end{array}$ \\
\hline 2 & $\begin{array}{l}\text { P1: It was like, it was nice to do something different... other than... like using the } \\
\text { skype }\end{array}$ \\
\hline 3 & $R:$ do you agree? \\
\hline 4 & All P: yes yeah yeah \\
\hline 5 & $\begin{array}{l}\text { P2: I thought it was quite sometimes a bit difficult to trying say, cause you know what } \\
\text { you'd say in English but then trying translating it to German. It was like a thinking... } \\
\text { you had to think what.... It was good to got your mind working. }\end{array}$ \\
\hline 6 & $R:$ So, how did you proceed? Did you, could you ask for words? \\
\hline 7 & P1: yeah, like certain words you could. \\
\hline 8 & $\begin{array}{l}\text { P2: Ehm, I liked working with other people in the class. So with my friends. And it was. } \\
\text { It wasn't awkward like. I felt comfortable and I thought, like, I could make mistakes } \\
\text { and they could still... It was more relaxed. }\end{array}$ \\
\hline
\end{tabular}


9 R: So it wasn't as confronting as spoken interaction?

10 P3: And it helped me learned new vocabulary and ehm eh like... even if you make mistakes they like. It could still be right.

11 R: So you said you learned some new vocabulary. Do you think you learned something from each other?

12 All P: yeah, yeah yeah...

13 P1: eh how like other people kind of write in German. How they structure their sentences.

14 P2: yeah yes...

15 P4: They helped some like with GCSE writings and that, sometimes speaking.

16 R: You said you've learned words? Did you look back how the sentences were built?

17 All P: yeah, yeah, yes

18 P3: like to see how different people would say the things like... because you'd see how they'd say it and then you'd see how you would write them and compare them and see which way is better so to think

19 R: Would you have learned more, if you had chatted with a native speaker?

20 P4: yeah, cause like, when we were talking to our friends, it was like more of a point of trying to get what you were trying to get across... rather than focusing on the grammar.

21 All P: yeah yeah

22 R: And you think when you had chatted with a native speaker you would do that more?

23 P2: yeah, and probably like work on the German more.

24 P4: It's like, there's someone who could correct you as well - if you do the sentences and so...

25 P3: yeah, and be more accurate

26 R: So did you look at that at all? Did you try to be accurate?

27 P1: It was harder

28 P3: We did try to be accurate but like. When the partner didn't understand then...

29 P4: I think it was more important that I got what I was trying to say across rather than it was completely right.

30 R: When you compare it to spoken interaction. What would have been different if you had talked to each other rather than chatted?

31 P4: you have to get the pronunciation right. And with the writing you just have to get the spelling right. So it's hard to say. It is a bit harder.

32 R: So, you think in spoken it would be harder?

33 P4: ehm, you'll learn

34 P1, P2, P3: spoken.

35 R: Are there other reasons why it is more difficult in spoken?

36 P1: I would actually say it is more difficult like writing, because, like, when you're speaking you can use gestures. Which you cannot do in writing.

37 P4: But I think like, you know when you've got it written down and you had some time, you'll think of it and you'll get back to the start and you'd had forgotten the word. When now I've got that bit now, what do I need?

38 And like with word order, you can see. Like, it helps me when you look at something. To know where to put the word and whether it looks right rather than if it sounds right That's just like for me.

39 All P: yeah..

40 P1: I was thinking you got a bit more time to think as well. Because when, like you're speaking you feel like you have to reply straight away. Whereas like when you're 
writing it, you can kind of take a minute time to think and then correct it. If you're wrong and then send it.

\begin{tabular}{l|l|}
\hline 41 & P3: yeah yeah.. \\
\hline 42 & $R:$ so was it boring
\end{tabular}

42 R: so was it boring to wait until the next answer of your partner was coming?

43 P1: I think it was quite a good way like. to see what they wrote and try to think of your answer and like to get it all out, like, send to them

44 P2: And when you see your answer. When you see their answer you can use that. When like, say if you're asking the questions and they're answering it. You can use that like what they said. And work on it.

45 R: Like you would copy it at bit?

46 P1: yeah, change it...

47 P3: It's also like you don't know what they're gonna send back, so it's kind of like put you on the spot and kind of like to see how you'd react and what happens in real life

48 P2: Like when you....when you're waiting for like someone else, I always looked at the paper next to me to see what they'd put and I'd see they have said that, I could may be use that and say it in a different way and to get some idea's

49 R: Are you normally in class a bit anxious to talk and now think, this is easier?

50 P2, P4: yeah, yeah...

51 P3: yeah, it's like a one-on-one thing

52 P1: yeah, easier

53 P2: It's nicer in smaller groups.

54 R: Thank you. 